\title{
Encuentros (polémicos) en el Pacífico entre viajeros ilustrados y nativos
}

\author{
FERNANDO MONGE \\ Instituto de Historia. CSIC. Madrid
}

\section{RESUMEN}

Este artículo aborda la peculiar naturaleza de los encuentros entre pueblos nativos del Pacífico y exploradores ilustrados, así como el modo en que esos exploradores y los antropólogos contemporáneos los han interpretado. No obstante y a pesar de la importancia que esos encuentros han tenido, el objetivo fundamental de este artículo es abordar cómo los antropólogos se han encontrado con el tiempo y cómo éste ha hecho evidente el modo en el que los antropólogos hacemos nuestras interpretaciones. Una parte importante del artículo se centra en la muerte del Capitán Cook y en la controversia que dicho acontecimiento provocó entre Sahlins y Obeyesekere.

Palabras clave: Métodos antropológicos, Historia de la antropología, Exploraciones ilustradas, Pueblos del Pacífico.

\section{SUMMARY}

This paper deals with explorers' encounters with natives in eighteenth century Pacific and how these encounters where interpreted by the formers and current anthropologists' as well. Though important as that encounters might have been, this paper is primarily concerned with anthropologist encounters with time and how such encounters have laid bare some of the way we do our interpretations. A big deal of the paper focuses on the death of Captain Cook and the Sahlins / Obeyesekere controversy prompted by the interpretation of this event.

Key words: Anthropological Methods, History of Anthropology, Enlightenment Explorations, Pacific Peoples.

LA METODOLOGÍA NO ES MÁS QUE LA HISTORIA DE UNA SUPERVIVENCIA

La metodología ha sido para la antropología como los decorados que construyen el escenario en el teatro. Se ven, pero no se tienen en cuenta

RDTP, LVIII, 1 (2003): 263-290 
porque, simplemente, son el contexto en el que las acciones de los actores, personas que queremos reales, materializan una serie de comportamientos mediante conflictos o tramas, historias en las que podemos vernos reflejados. Esta imagen de la que me valgo, que se puede encontrar en el origen de ciertas escuelas o tendencias antropológicas, como es el caso de la antropología simbólica de Victor Turner o de la sociología de Erving Goffman, está profundamente relacionada con el desarrollo de la antropología en general. En la tremenda variedad a través de la cual hemos navegado, tras aproximarnos o abordar brevemente distintas perspectivas metodológicas que tienden a corresponderse con escuelas y teorías a menudo tan diversas como sus métodos, permanecen, en mi opinión, algunas constantes que no voy a desglosar ahora ya que son visibles a lo largo de las distintas contribuciones que componen este libro.

Sin embargo, hay un aspecto que sí creo necesario destacar: la unidad de la antropología en su diversidad se manifiesta no sólo en la constante tendencia a problematizar aquello que estudiamos sino, también, por tratar de ir más allá de lo que otras humanidades y ciencias sociales tienden a considerar en sus investigaciones. Los antropólogos somos como esos niños que no sólo se conforman con jugar con sus juguetes, sino que, además, quieren mirar en su interior sin destruirlo.

A diferencia de ciertas visiones esencialistas o fundamentalistas de nuestra disciplina, aficionadas a dejar fuera de la misma todo lo que no se encuadra dentro del patrón clásico de la antropología (la que imaginamos con el intrépido antropólogo vestido con su uniforme oficial, haciendo trabajo de campo en exóticos y lejanos territorios descolgados del mundo moderno o de la historia y, una vez retornado a nuestro mundo, redactando una brillante monografía que nos convierte en la voz de los nativos $\mathrm{X}$ ), presentamos en estos textos un panorama complejo, controvertido, sin fórmulas magistrales, es decir, una perspectiva de una disciplina que, como diría Clifford Geertz, es poco disciplinada ${ }^{1}$. Tanto es así que hoy reconocemos a nuestro objeto de estudio como sujeto e interlocutor, no importa su procedencia o legitimidad social. Hemos mostrado cómo nosotros, los propios antropólogos, entramos ahora en el retrato que elaboramos y también cómo esa elaboración explícita es parte de nuestro trabajo. De algún modo la antropología ha pasado de ser de uno de esos museos tradicionales, con las obras en su interior, a una suerte de Centro Pompidou, un espacio de exhibición de las artes visuales en el que las obras de arte se encuentran tanto dentro como fuera de un edificio dado la vuelta, es decir, que muestra en sus fachadas lo que antes se

\footnotetext{
${ }^{1}$ Véase el capítulo dedicado a las "disciplinas" y, en particular, Geertz (1995: 96-99).
} 
ocultaba: sus "tripas", las conducciones del agua o el aire acondicionado, la electricidad y todos los servicios que lo convierten en "habitable".

Los nuevos campos de la antropología, gracias al desarrollo de metodologías, como las que nos permiten analizar trabajos con textos o abordar teóricamente el cambio y el paso del tiempo en las sociedades y culturas; o valernos de fuentes de información más variadas o imaginativas a veces que el informante o el archivo, me llevan a centrar mi texto en torno a un elemento clave de la práctica antropológica: el problema de la interpretación.

La antropología es una disciplina que, tal como indica una de las definiciones más convincentes que he leído en los últimos años, se ocupa de "las relaciones [existentes] entre la sociedad y la cultura", es el "estudio comparativo del sentido común, tanto es sus formas culturales como en sus efectos sociales" (Herzfeld 2001: x). Desde una perspectiva antropológica el "sentido común" es un término, como dice Michael Herzfeld, particularmente mal denominado, ya que ni el "sentido común" es común para todas las culturas, ni tiene sentido más allá de la cultura particular en el que se desarrolla (Herzfeld 2001: 1-6). Aplicamos a lo largo de nuestra vida cotidiana el sentido común para comprender cómo funciona, qué significa el mundo en el que vivimos, qué esperamos de él y cómo nos situamos en el mismo, sin embargo, tan pronto como nos embarcamos en una actividad antropológica descubrimos que el mundo, o mejor dicho, cómo lo percibimos y vivimos, es tan variado como arbitrario. De hecho, su diversidad puede trazarse dentro incluso de unidades sociales o culturales específicas.

A lo largo de los años, la antropología se ha ido haciendo consciente de sí misma, de su actividad y de su posición en un mundo cada vez más interconectado. Los "otros" que conformaban nuestro objeto de estudio ya no son criaturas descolgadas de un espacio que visitábamos los antropólogos durante periodos bien definidos. Tampoco habitan un tiempo sin tiempo que construimos como una ficción etnográfica para describirlos y, luego, analizarlos para ponerlos en conexión con otros pueblos sin historia dentro de una suerte de tabla periódica de los elementos o pueblos de interés antropológico. El giro reflexivo en la antropología, ha recolocado a los antropólogos dentro de su obra, nos ha hecho reflexionar y reflejarnos en nuestro trabajo. La antropología de la escritura nos hacía ver cómo nuestra actividad requería de la escritura y cómo la narración era un elemento clave de nuestras estrategias diseñadas para dar verosimilitud a nuestro "yo estuve allí". Nuevos medios de registro de los "otros", como el vídeo, han desarrollado de modo explosivo subespecialidades como la antropología visual y han hecho más evidente que la 
antropología tiene una faceta de experimentación que también conviene explorar. Los compromisos de los antropólogos con las comunidades sobre las que investigan nos recuerdan la dimensión crítica de nuestro ejercicio y ponen en comunicación a la etnografía con las nuevas escuelas de pensamiento cultural crítico, los estudios de género, postcoloniales, subalternos y los postmodernismos.

La historia de la antropología se ha convertido, durante los últimos años, en una suerte de maremagnum, donde a veces, es difícil percibir la materia esencial de la que se compone la disciplina. Su actividad tradicional, tal como la entendemos hoy no ha perdido valor o utilidad social, sin embargo, su actitud crítica, poco disciplinada y poco apegada a las formas de legitimación científica que la encumbran en la academia y la permiten ofrecerse como una actividad socialmente valiosa y reconocida, han provocado más que una crisis de la actividad antropológica, una devaluación de su dimensión pragmática. Resulta en mi opinión muy paradójica esta situación en unos momentos en que ciertos conceptos claves de la antropología, como son la cultura, la etnicidad y los grupos étnicos, o principios como el relativismo cultural, colonizan o se han extendido a otras disciplinas e, incluso, en el uso popular. No quiero entrar aquí en estas complejas y controvertidas cuestiones, lo que me preocupa, antes de introducirnos en los territorios que me he propuesto explorar, no es más que hacer bien visible el peculiar modo en que la antropología percibe sus dimensiones teóricas y prácticas, ya que de hecho, y tal como defienden muchos especialistas ${ }^{2}$, la antropología es una teoría de la práctica, las "respuestas" que podemos dar sobre la naturaleza del hombre son limitadas y se ciñen a los temas que tratamos.

La etnografía no es más que una práctica antropológica que nos permite abordar un tema de estudio, relacionarnos con seres humanos y dar un sentido a las formas culturales y reglas o prácticas sociales en las que viven. Con la etnografía presentamos otras comunidades, que pueden ser la nuestra, a otras personas; mostramos el "sentido común" que habita sus vidas y aprendemos sobre nosotros mismos. Todas las transformaciones a las que me he referido hasta ahora se traducen en una etnografía que no representa a las comunidades en un espacio sin tiempo, la cultura está viva y es dinámica, es rechazada y modificada, tanto por aquellos

\footnotetext{
${ }^{2}$ Si bien uno de los antropólogos que defiende con más vigor esta idea es Michael Herzfeld, no es difícil encontrar otros que, de modo implícito e explícito, coinciden en este punto. De hecho, la insistencia en el trabajo de campo como elemento clave no sólo de nuestra disciplina sino, también, como estadio fundamental de la formación del antropólogo.
} 
que la viven, como por otros que no pertenecen a la misma. Es obvio que se abren ante nosotros múltiples alternativas de trabajo, tantas, al menos, como modos de exponer los resultados de nuestra actividad. Ahora bien, en los pasos que nos llevan de la antropología a la práctica etnográfica, en el mismo centro de nuestro modus operandi se encuentra, como ya había mencionado, la interpretación de aquello con lo que nos relacionamos, del problema que enfrentamos.

Durante los últimos años la etnografía, la antropología en suma, ha ampliado mucho, no sólo los ámbitos en los que trabaja, sino, también, las fuentes de las que extrae su información y trata de establecer su relación con ese "otro" ya no tan distante. Hoy numerosos antropólogos trabajamos no sólo con personas vivas sino con archivos, monumentos o, incluso, con comunidades ciberespaciales. Los archivos no son sólo el espacio de los etnohistoriadores ${ }^{3}$ en el sentido clásico del término, son también uno de los lugares gracias a los cuales podemos desarrollar una antropología histórica o, incluso, antropología social o cultural en general.

A mediados de los años ochenta numerosos antropólogos, hasta entonces anclados en una práctica que tenía como base el trabajo de campo clásico, es decir, que se caracterizaba por una estancia más o menos prolongada en un lugar exótico, comenzaron a interesarse por y percibir una serie de dimensiones nuevas en su actividad. Las sociedades, las culturas que estudiaban no eran mundos prístinos, separados de otros grupos y anclados en un tiempo mítico: muchos de ellos se habían constituido en naciones y reclamaban una visión propia y nueva de sí mismos. Dentro de nuestros países los grupos exóticos, es decir marginados y minoritarios, recibían una atención renovada; surgían, de hecho, nuevas áreas etnográficas como la mediterránea y nuevos campos de estudio. No voy a entrar en las razones de estos cambios que ya he esbozado en los párrafos anteriores, ni a centrar en estos años unas transformaciones que han tenido lugar a lo largo de, al menos, cuarenta años. En la década de 1980 la antropología no sólo descubría, sino que reivindicaba, también, el archivo y los textos escritos como uno de nuestros nuevos lugares de trabajo de campo. Tras esta reivindicación "jurisdiccional" subyacía una necesidad analítica y teórica elemental: integrar en nuestro ámbito de análisis el tiempo. Los nativos, es decir, aquellos que estudiábamos, que no sólo eran indios o pueblos del mediterráneo, eran también habitantes de las ciudades, inmigrantes, gente, en suma, con historia. En 1982, apa-

3 Véase a este respecto un interesante número especial dedicado a la etnohistoria de la revista Desacatos. Revista de Antropología Social, 7: "Etnohistoria" (Otoño 2001). México D. F.: Ciesas. 
recía uno de los grandes manifiestos de la antropología histórica: Europa y los pueblos sin historia, escrito por Eric Wolf. En esta síntesis de la historia de la expansión occidental durante los últimos quinientos años, se analizaba cómo los pueblos que encontraron los europeos desde mediados del siglo XV no sólo tenían una larga e interesante historia propia, sino cómo fueron transformados tras su inclusión en lo que voy a denominar, sin demasiada precisión, ese nuevo sistema mundo. Más allá de la particular perspectiva teórica y analítica del autor, Eric Wolf, nos ofrecía una síntesis general y abría nuevas dimensiones a un debate en el que la voz propia de los otros iba adquiriendo un cada vez mayor peso específico.

Pero, ¿cómo se producía el contacto?, ¿cómo se integraban las historias de unos y otros bajo el dominio colonial occidental?, ¿todos los "nativos" tienen historia?, ¿existe un tipo de historia único? o, por el contrario, cada pueblo tiene un modo de percibir su historia. ¿No estamos confundiendo historia con la simple memoria oral del pasado, o con la pura y dura mitología? ¿Cuántas historias distintas puede tener un solo pueblo? Los problemas que generaban a los antropólogos esas miradas al pasado eran múltiples y no surgían sólo como consecuencia de las modificaciones que imponían los textos escritos a nuestra tarea etnográfica sino, sobre todo, por la existencia de una serie de problemas teóricos y metodológicos de mucho mayor calado, ya que describir a los otros no se limitaba a reivindicar el consabido "yo estuve allî" y esto es lo que ví.

\section{El PACÍFICO}

Por paradójico que pueda parecer, el Pacífico, uno de los lugares más prominentes para la antropología, cuna del trabajo de campo clásico, de

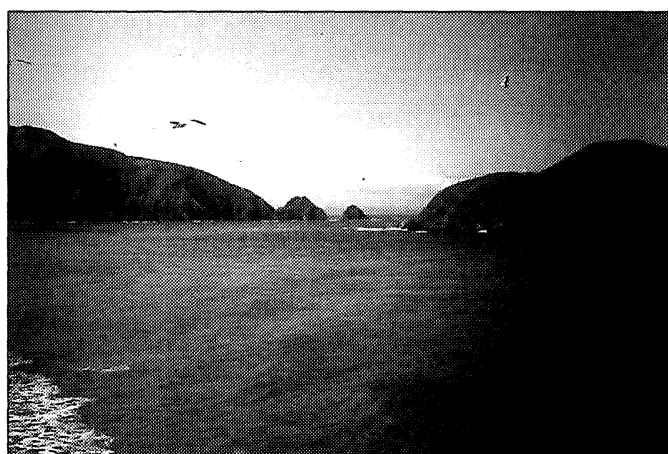

Figura 1.-Cook Strait. Entrada de Charlotte. Nueva Zelanda. las monografías de sociedades y culturas descolgadas del espacio y del tiempo fue también una de las primeras áreas del mundo en las que se comenzó a reconocer la dimensión histórica de los pueblos sin historia. Quiero presentar dos casos de estudio de un Pacífico y una antropología renovada gracias a una de las polémicas más 
sonadas e importantes de los años ochenta y noventa, y que se centró en una verdadera batalla entre su "instigador", Marshall Sahlins y su máximo, aunque no único, contrincante, Gananath Obeyesekere ${ }^{4}$.

Marshall Sahlins ${ }^{5}$ es, sin lugar a dudas, uno de los antropólogos más inquietos del panorama internacional ${ }^{6}$. Experto en las culturas aborígenes del Pacífico, revolucionó las perspectivas que teníamos sobre la economía de las sociedades de, como él las denomina, la "edad de la piedra". En su libro Economía de la edad de piedra defiende no sólo la afluencia económica de sociedades cazadoras y recolectoras sino, sobre todo y lo que es más importante desde una perspectiva general, que la economía "es una categoría de la cultura más que del comportamiento, de la misma clase que la política y la religión más que la racionalidad o la prudencia: no son las actividades de servicios necesarios que requieren los individuos, sino los procesos de la vida material de las sociedades" (Sahlins 1974: xii). Desde posiciones teóricas que le convierten en uno de los líderes de la escuela de pensamiento teórico del evolucionismo cultural ${ }^{7}$, Sahlins avanzará a lo largo de su carrera tesis que, progresivamente, van incluyendo dentro del dominio de la cultura otras facetas de la actividad humana. Así, entrará durante la década de los setenta del siglo XX en dos polémicas de notable impacto con Marvin Harris, primero, en la que

${ }^{4}$ La polémica, que se ha centrado fundamentalmente entre Sahlins y Obeyesekere, ha tenido otros muchos participantes y comentaristas. Este trabajo se centra fundamentalmente en la "segunda fase", la que protagonizaron Sahlins y Obeyesekere y, dentro de la misma, en aquellos aspectos de una dimensión más general y orientada al problema de la interpretación. Los hitos básicos en torno a los que se centra la polémica son: Sahlins $(1985,1988,1989,1995,1997)$ y Obeyesekere $(1992,1997)$. Para tener una perspectiva general, en las que se incluyen textos de Sahlins, Kane y Obeyesekere, véase el artículo de Robert Borofsky (1997).

${ }_{5}^{5}$ Otra perspectiva de la evolución del pensamiento de Sahlins con respecto a la cultura es la de Adam Kuper (1999: 159-200). Tal como sintetiza este autor, Sahlins convierte a la historia en cultura y le preocupa, a diferencia de otros comentaristas sobre la polémica, la dimensión teórica de la cultura en su concepción del análisis de los procesos históricos, por ello, centra su interés en un texto de Sahlins con más desarrollo teórico sobre los aspectos que le preocupan: Historical Metaphors and Mythical Realities: Structure in the Early History of the Sandwich Island Kingdom, (Sahlins 1981). Aborda también de modo explícito la polémica de Sahlins con Obeyesekere (Kuper 1999: 190-200).

${ }^{6}$ Adam Kuper (1999) traza en un capítulo el modo en el que Marshall Sahlins se ha relacionado y concebido la cultura. Contiene, por supuesto, una sección importante en el mismo, dedicada a la polémica entre este antropólogo y Obeyesekere.

7 Alumnos de Leslie White y Julian Steward, son "compañeros" del círculo figuras como Marvin Harris, Sidney Mintz, Roy Rappaport, Elman Service y Eric Wolf (véase Kuper 1999: 159 y ss.). 
ataca su explicación exclusivamente materialista y económica de cualquier fenómeno cultural, y, con Edward $\mathrm{O}$. Wilson ${ }^{8}$, después, ante la defensa que hace éste de la raíz e importancia de la dimensión biológica en el desarrollo y características de la cultura humana. En ambas subyacía un mismo tema: la importancia de la cultura y de su poder simbólico como eje ordenador que confiere sentido al mundo que habitamos y al orden social en el que nos reproducimos.

En su opinión, y este es el preámbulo de su "retorno" al Pacífico como área de estudio: "El gran desafío para [el desarrollo] de una antropología histórica no es simplemente cómo la cultura ordena los acontecimientos, sino cómo, en ese proceso, la cultura se reordena a sí misma. ¿Cómo es posible que la reproducción de la estructura se convierta en su transformación?" (Sahlins 1981: 8). O dicho de un modo más cercano a la práctica y las investigaciones de caso, ¿cómo combinar la descripción y análisis históricos con los de la antropología? ¿De qué modo podemos mezclar diacronía con sincronía, la memoria escrita con la oral, los dibujos neoclásicos de los aborígenes que se realizaron en el siglo XVIII con sus manifestaciones artísticas, el poder colonizador con la marginalización y transformación de los colonizados?

Para un experto en el Pacífico, la entrada de los occidentales en la historia y vidas de las sociedades insulares, los primeros encuentros entre los expedicionarios ilustrados, vanguardia no sólo de la modernidad y la dominación colonial sino, también de la descripción etnográfica bajo unos postulados muy cercanos a los clásicos de la antropología ofrecían, sin lugar a dudas un ámbito extraordinario de estudio. $\mathrm{Y}$ entre todos esos encuentros, pocos exploradores, por no decir ninguno, destacaban más que el Capitán Cook. Hijo de granjeros de tierra adentro, en la frontera con Escocia, James Cook es uno de esos escasos ejemplos de ascenso social, gracias a sus dotes marineras y como explorador dentro de las escalas de la Armada británica. Cook, tal como dice un breve resumen de sus contribuciones a los descubrimientos del Pacífico:

- descubrió Hawai ${ }^{9}$, la Isla de Navidad, Nueva Caledonia, las islas Cook, Gilbert, parte de las Tuamotus, Fiji, y las islas Tonga.

\footnotetext{
${ }^{8}$ La obra que genera la enérgica reacción de Sahlins no es otra que: Sociobiology: The New Synthesis de Edward O. Wilson (1975).

${ }^{9}$ Algunos autores españoles sostienen que estas islas ya habían sido descubiertas, o avistadas, y nombradas por varios exploradores españoles desde el año 1529 (Landín 1984: 75). Según esta misma fuente, se las llamó islas de los Amigos (no confundirlas con las de Tonga) o de los Jardines, e individualmente como La Mesa, Los Majos (quizás Monjes) y La Desgraciada.
} 
- redescubrió las Marquesas, las Solomón, y la isla de Pascua ${ }^{10}$.

- probó la inexistencia del gran continente austral [Terra Australis Incognita].

— probó que Nueva Guinea y Australia no eran parte de la misma masa terrestre.

- demostró que Nueva Zelanda no era parte del gran continente austral y que se componía de dos islas principales.

- descubrió la dieta que prevenía el escorbuto ${ }^{11}$.

— descubrió el Antártico (Craig 1978: 33).

Sin duda alguna, las tres expediciones de Cook alrededor del mundo y su sistemática exploración del Pacífico, sus métodos de relación con los nativos, la actividad científica de algunos de los que le acompañaron, los artistas que por primera vez retrataron la naturaleza, los paisajes y las culturas del Pacífico están en el origen,

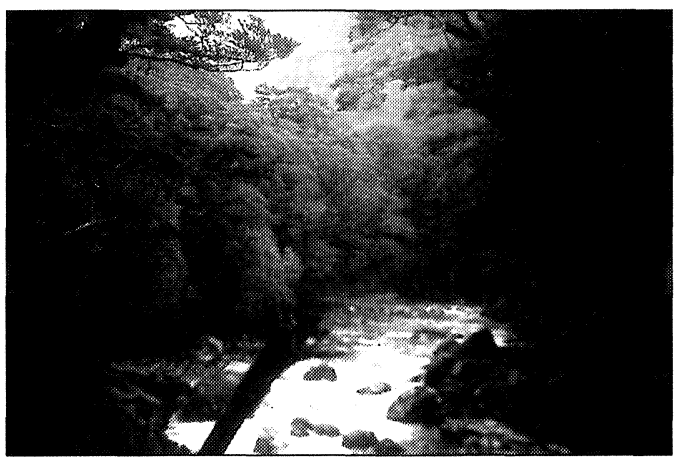

Figura 2.-Camino a Milford Sound. Río hacia Te Anan. Nueva Zelanda. no sólo de la segunda era de expansiones coloniales occidentales y británicas en esas aguas, que hasta entonces únicamente habían sido surcadas por naves españolas desde el siglo $\mathrm{XVI}^{12}$ y holandesas durante el siglo XVII, sino también de la imagen

${ }^{10}$ Uno de los problemas que se encontraron los exploradores oceánicos antes de que se desarrollara el reloj náutico y un método de medición preciso de la longitud en alta mar, era la "pérdida" de las islas descubiertas. Un pequeño error en la longitud la deslocalizaba o podía confundirla con otras. El caso de la isla de Pascua es uno de los más destacados, ya que, supuestamente descubierta por el piloto Juan Fernández en la segunda mitad del siglo XVI, fue redescubierta por el holandés Jacobo Roggeween (en 1722, durante la fiesta de la Pascua o Resurrección) y finalmente situada con precisión en un plano por James Cook (a pesar del reconocimiento, unos pocos años antes, de Felipe González). Para la localización de las islas del Pacífico, sus nombres y expediciones españolas véase Landín (1984).

11 Tras el retorno a Inglaterra de la segunda expedición (1772-1775) sin haber perdido ni un solo marinero por escorbuto recibió la mayor distinción británica a los logros intelectuales, la Copley Gold Medal, y fue nombrado miembro de la Royal Society, Post Captain de la Armada y recibido por el rey (véase Beaglehole 1974).

${ }^{12}$ Tanto es así que el Pacífico se denominó Mar Español. 
que todavía hoy tenemos de un océano que ocupa 166 millones de $\mathrm{km}^{2}$, cubre una tercera parte de la tierra y contiene aproximadamente la mitad del agua del mundo.

El Pacífico que conocemos, sobre todo aquellos que no proceden de él o lo han visitado, es, más que un lugar en sí mismo, un paisaje construido a lo largo de más de dos siglos por sus visitantes y colonizadores, elaborado por la ciencia y el arte, por la literatura y la música. Si partimos de las primeras expediciones que divulgan sus exploraciones, gracias a una literatura de narraciones de viajes —algunas de ellas ilustradas- de gran tirada y evidente valor estratégico, el Pacífico que podemos conocer es el producto de una literatura con un toque épico o moral muy característico de la novela del siglo XIX. Pero, a diferencia de ésta, más soterrado e inconsciente, teniendo en cuenta más bien la tendencia tan característica de la primera antropología profesional y universitaria, del moralismo y relativismo cultural comprometido con las culturas ajenas. Y será éste un campo donde se manifestará cierta dosis de etnocentrismo combinado con posturas éticas personales y obsesiones intelectuales.

"En el lado netamente artístico de la literatura encontramos un antecedente aparentemente claro de la etnografía polinesia, cuya buscada verosimilitud etnográfica enmascara el predominante interés de Herman Melville como explorador de los reinos de la oscuridad, dentro de la mente humana, más que de las doradas islas donde discurrió el crucial tiempo de su juventud", tal como indica en su introducción, George Woodcok (1983: 7), a la novela de Herman Melville (1983) Typee. A Peep at Polynesian Life. En la vertiente más decididamente científica y técnica, cuando menos en lo referente a su forma, podemos ubicar a los antropólogos cognitivos, mientras que en distancias intermedias entre ambos extremos, existe un gran volumen de obras que pueden ser consideradas el negativo de la novela, en tanto en cuanto la pretendida verosimilitud de lo narrado por el novelista es un efecto que permite acentuar lo emotivo y la cercanía del lector con respecto a los problemas morales y de los seres humanos (básicamente occidentales), frente al tono positivista y empírico basado en la meticulosa y prolongada visión de la realidad del antropólogo, en la que el autor introduce ocasionalmente notas personales de mayor nivel de lirismo, cuyo efecto es empatizar con el mundo descrito y analizado, con los problemas del trabajo de campo o ambos. Dentro de esta última alternativa podemos considerar el conocido y más clásico de los estudios sobre Tikopia de Raymond Firth, We, the Tikopia (Firth 1983, primera ed. 1936)" (Monge 1992: 101-102) ${ }^{13}$.

\footnotetext{
${ }^{13}$ He introducido en la cita algunas modificaciones de estilo.
} 
El Pacífico es también uno de esos lugares de nuestra niñez, de islas desiertas y "Robinsones Crusoes", de aventuras y libertad, de culturas no menos seductoras que sus habitantes. Ese escenario de nuestra infancia, forjado a partir de novelas y películas, terreno de luchas morales entre el bien y el mal, no está, sin embargo, tan lejos de la literatura científica ilustrada. Los mismos nombres de las islas reflejan nuestras percepciones: las positivas, como las islas de los Amigos (Tonga), las de la Sociedad, la nueva Citerea (Tahiti), Solomon o de la sabiduría; las negativas como las de los Ladrones; las religiosas, Pascua o Navidad, o las de homenaje, Cook, Marquesas, Sandwich (Hawai). En el Pacífico no sólo se desarrolló la ciencia: la medición de la longitud, la prueba de dietas antiescorbúticas, la investigación naturalista o el descubrimento de la teoría de la evolución, sino que se buscaron continentes nacidos de la ciencia —o imaginación- clásica, como la Terra Australis Incognita y pasos geoestratégicos vitales, como el del noroeste, que habrían de reducir las distancias de la navegación entre este océano y Europa. De hecho, dos de las expediciones de Cook y de las polémicas más agrias del explorador están fundamentalmente motivadas por estos sueños. Por ello, cuando nos aproximamos a estos textos hay que tener en cuenta el contexto en el que nacieron, ya que el Pacífico de los polinesios del siglo XVIII que tratamos de recuperar puede estar profundamente modificado por la percepción de nuestros ancestros. Sólo podemos saber de ese mundo interpretando, y es esa interpretación la que nos lleva al primer caso que quiero tratar aquí: cómo entender la muerte del capitán Cook en su tercera expedición a manos de los nativos en Hawai, y qué podemos aprender de ella.

\section{LA MUERTE DE COOK}

Cuando Cook y sus hombres descubrieron el archipiélago de Hawai en su tercera expedición (1776-1780) ${ }^{14}$ (18 de enero de 1778) no se po-

\footnotetext{
${ }^{14}$ Exploraron las islas y recalaron en Waimea, isla de Kauai, hasta el 2 de febrero de 1778. Tras su vuelta de la Costa Noroeste de América y de las islas Aleutianas, retornaron a las islas Hawai para invernar. Llegaron al archipiélago el 26 de noviembre de 1778 y navegaron entre las islas durante dos meses, hasta que los barcos recalaron en la bahía de Kealakekua el 17 de enero de 1779, permaneciendo allí hasta el 4 de febrero. Pese a recibir una excelente despedida, su permanencia ya era excesivamente prolongada. Desgraciadamente, menos de seis días después, ante la ruptura de uno de los mástiles del "Resolution" por culpa de una tormenta, Cook decidió retornar a la misma bahía para repararlo. El escenario que iba a llevar a la muerte de
} 
dían esperar mejores augurios: la privilegiada posición de éstas islas en el Pacífico las convertían en la mejor base desde la que partir en busca de un paso marítimo por el norte que uniera por una ruta más breve a la metrópoli británica con el Pacífico. Los nativos no podían ser más hospitalarios ya que, como el propio Sahlins relata a partir de distintos diarios de la expedición:

Fue la bienvenida más generosa que se haya brindado nunca a ningún viaje europeo de descubrimiento en este océano. "Anclados en 17 brazas de arena negra", dice el diario de navegación de un guardamarina, "en medio de una cantidad innumerable de canoas, ocupadas por personas que cantaban y se regocijaban todo el tiempo" (Riou, Diario de navegación: 17 de enero de 1779). ¡Cantaban! Nunca en toda su vida había visto el capitán Cook tantos polinesios reunidos como había allí, en la bahía de Kealakekua. Además de las incontables canoas, había polinesios subiéndose al Resolution y al Discovery, bordeando las playas y nadando en el agua "como cardúmenes de peces". Tal vez había 10.000, o el quíntuple de personas que normalmente vivían allí. Y no se veía una sola arma con ellos, observó Cook. En cambio, las canoas estaban cargadas de cerdos, batatas, frutos del árbol del pan, caña de azúcar: todo lo que producía la isla. También las mujeres "parecían notablemente ansiosas por relacionarse con nuestra gente" (Ellis, 1782, 1: 86). Un sacerdote subió a bordo y envolvió al capitán Cook en el decorado de tela de tapa roja perteneciente a la imagen de un templo, luego hizo la oferta de un cerdo sacrificatorio. En tierra, el sacerdote condujo al Gran Navegante de la mano hasta el templo de Hikiau. Cuando oía el grito del heraldo "Oh Lono", a su paso la gente huía a sus casas y se prosternaba con la cara contra el suelo. Lono es el dios asociado con el crecimiento natural y la reproducción humana que regresa todos los años a las islas con las fecundantes lluvias del invierno; es además un antiguo rey que viene en busca de su novia sagrada. En enero de 1779, en el templo se honró a Cook con los ritos de bienvenida habitualmente celebrados para Lono (Sahlins 1988: 105-06).

Cook, al integrarse y seguir el juego de la ceremonia del Makahiki, se había convertido en "la imagen de Lono" y, una vez más, el explorador, en su afán por conocer más a fondo y directamente las culturas que visitaba, no dudaba en participar y ser testigo de cuanta ceremonia o actividad tuviera lugar en tierra. En Hawai, la experiencia de los viajeros, pese a los conflictos ocasionales con los nativos (surgidos de los constantes robos a los que estaban expuestos los expedicionarios por parte de éstos), no pudo ser más placentera. Como en cualquier otra escala, llevaron a cabo sus actividades habituales: tareas de aprovisionamiento, aguada y reparaciones que debían emprender en tierra, localización

su comandante ya estaba listo, pues ni los nativos estaban dispuestos a recibir con los brazos abiertos a los expedicionarios, ni Cook parecía tener el talante dialogante y diplomático habitual. 
astronómica de las islas y elaboración de cartas naúticas y mapas, investigación de las características naturales de la isla así como de los habitantes que residen en ella, entablar una buena relación con los mismos. Cook, no sólo era un experto explorador, un consumado cartógrafo y un buen líder, según se observa en sus diarios y mapas y en los de sus compañeros, sino que además mostró una capacidad de descripción de las culturas y una perspicacia extraordinaria. Sin duda, su firmeza y dotes diplomáticas le ayudaron en el empeño.

Tras su estancia en la bahía continuaron navegando hacia el norte, pero la fatalidad quiso que el mástil de una sus naves, el Resolution, se rompiera ${ }^{15}$ y Cook decidió retornar al mismo lugar en el que tan buen trato habían recibido. ¿Qué había pasado durante la ausencia de los expedicionarios para que fueran recibidos primero con sorpresa, y luego de tan malos modos? ¿Cuáles son los acontecimientos y las razones que llevaron a un enfrentamiento con los nativos que acabó con las vidas de Cook, varios nativos y expedicionarios?

Según Marshall Sahlins:

La muerte de Cook a manos de los hawaianos sólo unas semanas después [de su llegada] podría describirse como una secuela ritual: la metáfora histórica de una realidad mítica. Los mitos no eran sólo hawaianos. [...] Un domingo temprano por la mañana, el 14 de febrero de 1779 , el capitán Cook bajó a tierra con una partida de marineros para tomar al rey hawaiano Kalaniopu'u como rehén hasta que le devolviesen el bote del Discovery, robado la noche anterior en una audaz maniobra; de lo cual, sin embargo, el viejo y amistoso gobernante era inocente. En el momento decisivo, Cook y Kalaniopu'u, el Dios y el Rey, se enfrentarán como adversarios cósmicos. Permítaseme una lectura antropológica de los textos históricos. Pues en todas las confusas narraciones tolstoianas de la refriega [...] la única certidumbre recurrente es una estructura dramática con las propiedades de una transformación ritual. En el trayecto hacia el interior de la isla para encontrar al rey y de allí hacia el mar con su rehén real, Cook sufre una metamorfosis: de ser objeto de veneración a objetivo de la hostilidad. Cuando bajó a tierra, la gente común se dispersó como de costumbre ante su presencia y se prosternó con la cara contra el suelo; pero al final, él mismo fue precipitado con la cara contra el agua por el arma de un jefe, un punal de hierro comercial, siendo arrollado por una multitud triunfante, que parecía querer aumentar sus propios honores por la parte que pudiera reclamar de su muerte: "arrebatándose los puñales unos a otros", dice el informe del señor Burney "en la ansiedad por participar en su matanza" (Diario: 14 de febrero de 1779). En la inversión ritual final, el cuerpo de Cook sería ofrecido en sacrificio por el rey hawaiano (Sahlins 1988: 106).

\footnotetext{
${ }^{15}$ Los problemas que tuvieron con los barcos antes de partir y el mal estado de los mismos es una de las características más llamativas de la organización de esta tercera expedición de Cook. Véase, Beaglehole (1967 y 1974).
} 
Para aquellos de nosotros, tanto historiadores como antropólogos, que nos hemos dedicado a investigar y conocer más a fondo el Pacífico, la muerte de Cook es un acontecimiento particularmente amargo. Para un lector de los diarios de Cook, su muerte es un final que no sólo genera tristeza, sino también perplejidad. A pesar de los malos presagios y dimensiones coloniales de la actividad de Cook, sus textos ofrecen a los lectores una mina de información, unos acontecimientos y una perspectiva del Pacífico en esa etapa del siglo XVIII absolutamente inigualable. Pese a los muchos aspectos negativos que se desprenden de sus exploraciones no es difícil entusiasmarse con sus logros, agradecer sus descripciones que le muestran como un visitante amable y empático con el mundo que se encuentra. Sin embargo, no debería sorprendernos tanto su muerte; de hecho, no es más que un accidente fortuito, al menos, eso nos dice nuestro "sentido común". No obstante, nos preguntamos ¿cómo fue posible que le pasara esto a Cook? Del mismo modo que en los Estados Unidos la repetición incansable de las imágenes del asesinato de John F. Kennedy es acompañada por la pregunta de ¿Quién asesinó al presidente?, nosotros nos preguntamos releyendo el final de Cook ¿por qué? ¿qué pasó realmente?

Nadie, hasta la publicación de las interpretaciones de Sahlins, se había atrevido a sugerir siquiera una explicación que combinara a visitantes y visitados, que tratara de integrar los universos culturales y, esto es más sorprendente todavía, la intersección de las historias de ambos pueblos en el momento del contacto ${ }^{16}$. Es interesante destacar que el libro Islas de Historia, que generó el estallido de la gran polémica que habría de durar más de diez años (de 1985 a 1997, aproximadamente), contenía mucho más que la descripción e interpretación de la muerte del capitán Cook. De hecho, el texto no es más que la recopilación de una serie de artículos y conferencias que desarrollan sus ideas sobre la interrelación entre la historia y la antropología, a los que añade una introducción donde expone su perspectiva:

La historia [volvemos a las propias palabras de Sahlins] es ordenada por la cultura, de diferentes maneras en diferentes sociedades, de acuerdo con esquemas

${ }^{16}$ Sahlins, desde hace varios años venía aproximándose a una interpretación tan sorprendente como integradora. La primera versión de la muerte de Cook aparece en 1978 con el título "The apotheosis of Captain Cook" en la revista Kroeber Anthropological Society Papers 53-54: 1-31. Un año más tarde, con el mismo título en francés, se publica en La fonction symbolique, Michel Izard y Pierre Smith (eds.). París: Gallimard: 306-43. Según manifiesta el propio Sahlins, el texto donde aborda con mayor detalle la estancia de Cook en Hawai y su asociación con Lono es: "Captain Cook at Hawaii", Journal of the Polynesian Society 98 (1989): 371-425. 
significativos de las cosas. Lo contrario también es cierto: los esquemas culturales son ordenados por la historia, puesto que en mayor o menor grado los significados se revalorizan a medida que van realizándose en la práctica. La síntesis de estos contrarios se desarrolla en la actividad creativa de los sujetos históricos, los individuos en cuestión. Pues, por una parte, la gente organiza sus proyectos y da significación a sus objetos a partir de los conocimientos existentes sobre el orden cultural. En esa medida, la cultura se reproduce históricamente en la acción. [...]. Por otra parte, entonces, como las circunstancias contingentes de la acción no tienen por qué coincidir con la significación que algún grupo podría asignarles, los individuos reexaminan creativamente sus sistemas convencionales. $\mathrm{Y}$ en esa medida, la cultura se ve históricamente alterada en la acción. Podemos hablar incluso de "transformación estructural", puesto que la alteración de algunos significados modifica las relaciones posicionales entre las categorías culturales, produciendo por consiguiente un "cambio del sistema" (Sahlins 1988: 9).

A Sahlins lo que más le preocupaba, como indica más adelante en el texto, es la cuestión de "la existencia dual y la interacción del orden cultural instituido en la sociedad y el vivido por los individuos: la estructura según la convención y según la acción, como potencia y como acto. Las personas, en sus proyectos prácticos y dentro de su organización social, estructurados por los significados admitidos de las personas y las cosas, someten esas categorías culturales a riesgos empíricos. En la medida en que lo simbólico es, de este modo, lo pragmático, el sistema es una síntesis en el tiempo de la reproducción y la variación" (Sahlins 1988: 10). Nuestra vida diaria, la historia, pone en peligro el mundo cultural y social en el que vivimos. El tiempo vuelve frágil las estructuras en las que nos reproducimos e intentamos reproducir. Desde esta perspectiva, el paso de Cook de ser un dios a una víctima de sacrificios es muy pequeño y puede interpretarse desde una suerte de lógica coyuntural: El rey de Hawai, sin saber con claridad si era un rehén, acompañaba a Cook.

Hasta ese momento nada había despertado las sospechas del rey y también recién ahora, relata Phillips, "empezamos a sospechar que no estaban tan bien dispuestos hacia nosotros". La transición llega repentinamente, en el momento en que se hace que el rey perciba a Cook como su enemigo mortal. Esta es la crisis estructural, cuando todas las relaciones comienzan a cambiar sus signos. En consecuencia, los intercambios materiales transmiten ahora cierta ambigüedad, como esos sacrificios maories que contaminan a los dioses en el acto de apaciguarlos. Un anciano ofrece un coco, cantando con tanta persistencia que el exasperado Cook no puede hacerlo callar ¿una súplica pidiendo que libere al rey? El teniente Phillips pensó que "un ingeniosos sacerdote bribón" lo hacía para distraer la atención del hecho de que sus compatriotas, reunidos en un número de dos o tres mil, se estaban armando para defender a su rey. Más o menos por esta época llega la noticia de que un importante jefe ha sido muerto por los británicos que se hallaban bloqueando el extremo sur de la bahía. El rey sigue sentado en el 
suelo "con las más fuertes señales de terror en su expresión" (Cook y King, 1784, 3: 44), pero pronto desaparece de la escena. Los acontecimientos se han desbordado escapando al poder de control de todos. "Los nativos" están manifestando esa disposición que los ingleses llaman "insolencia". El homenaje final a Cook es presentado en proyectiles que incluyen piedras y palos entre los trozos de frutos del árbol del pan y cocos. Al responder cada bando violentamente a las amenazas que perciben del otro, pronto llega el "impacto fatal" (Sahlins 1988: 107).

Para entender la muerte de Cook tenemos que entender la muerte de Lono. La excepcionalidad de este acontecimiento, la muerte de Cook a manos de los nativos, se inscribe en un acontecimiento recurrente, una ceremonia anual, que se representa colectivamente. Ese acto individual y contingente se convierte en algo histórico cuando adquiere un valor específico dentro de un proyecto cultural. Desde esta perspectiva Cook es más que un individuo, ya que tiene una lógica y su acción un significado dado dentro de una dimensión cultural específica. En los casos de encuentro que me ocupan, que son los mismos que generaron la polémica entre Cook y Obeyesekere, hablamos de dos sistemas culturales en contacto, de las acciones de los individuos y de una comunicación con significados divergentes para cada una de las partes que se encuentran.

El paso de Cook de la vida a la muerte es sólo un ejemplo que nos muestra un modo de entender la historia del contacto entre los occidentales y los nativos, entre la expansión colonial occidental y las "islas sin tiempo". Sin duda, el debate que suscitó la interpretación sobre la muerte de Cook ha sido objeto de interés preferente para aquellos antropólogos e historiadores dedicados al Pacífico o a la historia de la expansión colonial, sin embargo, la atención y el número de personas que han participado en él excede en gran medida a los especialistas del área. De hecho, el propio Obeyesekere, el otro polo de la polémica, no es un experto en la zona.

Antes de entrar de lleno en las réplicas que sufrió Sahlins quiero destacar dos aspectos profundamente interrelacionados y que, en mi opinión, son claves dentro del debate: las dimensiones teóricas y metodológicas que los llevan a chocar frontalmente pese a que, como pretendo mostrar al final, no están tan alejados el uno del otro como pueda parecer a primera vista. La controversia ${ }^{17}$ surge inicialmente en torno a dos cuestiones. Por una parte, algunos expertos dudan de lo vinculantes que pueden ser las estructuras culturales hawaianas a la hora de determinar

${ }^{17}$ La mejor síntesis que, en mi opinión, se ha publicado sobre este debate es la de otro antropólogo especialista en el área; se trata de la ya mencionada de Robert Borofsky (1997). 
el comportamiento de los nativos (Dening 1982); por otro, las divergencias se centran en el análisis que se ha hecho de los datos históricos (Friedman 1985; Bergendorff, Hasager y Henriques 1988). Estas primeras réplicas, que son contestadas por Sahlins en su libro Islas de Historia y en artículos de revistas dedicadas al área, mantienen el debate dentro de un nivel local o de área, pese al calado de las críticas.

En 1992, un antropólogo de Sri Lanka y profesor en la Universidad de Princeton publica un libro: La apoteosis del Capitán Cook. Construcción de mitos europeos en el Pacífico. La polémica entra en una nueva fase, desde hacía años no se leía en el mundo académico un ataque más devastador y sistemático a los planteamientos de un antropólogo de reconocido prestigio. Este libro, que fue objeto de al menos 29 reseñas en el mundo académico anglosajón ${ }^{18}$, en general muy positivas, y dos premios $^{19}$, trasladó la polémica a una escala distinta. Se convertía ahora en un choque entre dos personalidades de la disciplina, una confrontación personal muy dura y con argumentos de mayor profundidad que los que hasta el momento se habían manifestado. Obeyesekere se sentía enormemente irritado por el modo en que Sahlins interpretaba el comportamiento de los hawaianos, le parecía tan imperialista como el propio Cook. Sentía una profunda ira por el modo en que Sahlins había proyectado un mito europeo sobre unos "salvajes" atrapados por la lógica de los mitos y no, como Obeyesekere defiende, por un sentido práctico y una visión objetiva del mundo como los que los textos hacen exhibir a los exploradores.

Para Obeyesekere eran los europeos los que habían creado el mito de Cook, un Cook que fue confundido, según los visitantes y no los nativos, con el dios Lono, cuyos rituales supuestamente se llevaban a cabo en esa época del año. Son los occidentales los que han creado esa imagen de ellos mismos y -continúa afirmando- al considerar que son los nativos los que nos perciben como dioses, no sólo les enajenamos su voz, sino que los reducimos a criaturas sin sentido pragmático. Los hawaianos son, al igual que cualquier otro pueblo de la tierra, capaces de aplicar lo que Obeyesekere llama "raciocinio práctico" (practical racionality) ${ }^{20}$. El autor se sentía furioso, no sólo por razones intelectuales, como nativo de Sri

\footnotetext{
${ }^{18}$ Recojo esta información del artículo de Borofsky (1997: 256).

${ }_{19}$ Uno de ellos el premio Louis Gottschalk de la American Society for EighteenthCentury Studies (Borofsky 1997: 256).

${ }^{20}$ Él mismo lo define como: "[...] el proceso por el cual los seres humanos evalúan de modo reflexivo las implicaciones de un problema con criterios prácticos" (Obeyesekere 1992: 19).
} 
Lanka sabía que sus compatriotas nunca habían considerado a los colonizadores como dioses o semidioses, que no eran esclavos de los mitos, que la antropología no tenía que hacerle el juego al colonialismo. Ya estaba bien de considerar a los nativos, a los no occidentales, como criaturas de otro mundo. Obeyesekere en su libro les defendía como iguales a los occidentales, movidos por los mismos hilos, pragmatismo y racionalidad. Su reacción, tal como muestran las reseñas y premios que recibió, no podía haber sido mejor acogida por la academia.

El gigante Sahlins y su modelo de integrar historia y antropología, parecía, si nos limitamos al texto de Obeyesekere, muerto. La progresión teórica de Sahlins a la que aludíamos antes, su obsesión por subordinar a la cultura cualquier otra dimensión de la actividad humana, en el caso de la historia, le llevaba a defender una posición tan absurda como imperialista y etnocéntrica. Vivimos una nueva era y debemos desembarazarnos de esos viejos resabios interpretativos. Sin embargo, la polémica no iba a morir así, unos años después, en 1995, Sahlins publica la contestación a la apoteosis: Cómo piensan los nativos, por ejemplo, sobre el capitán Cook. Estaban en juego cuestiones centrales en antropología ¿tenemos los antropólogos derecho a hablar de los otros? ¿qué ocurre cuando las interpretaciones de unos y otros son divergentes?

Las cargas de profundidad que Obeyesekere lanzaba a los planteamientos teóricos de Sahlins ponían en cuestión todo un modo de hacer antropología e historia. Los nativos, las clases subalternas, los oprimidos, no podían ser interpretados desde una práctica antropológica como la que propone Sahlins:

Una de mis suposiciones básicas [dice Obeyesekere] es que hacer mitos, mitologizar, eso que los expertos asumen como una actividad fundamentalmente existente en sociedades no occidentales, es una realidad muy común en el pensamiento europeo. Un mito, en el sentido poco preciso y convencional del término, es generalmente una historia sagrada sobre dioses y ancestros fundadores, o historias sobre héroes ancestrales (leyendas). De acuerdo con la primera definición no hay muchos mitos en el pensamiento europeo. Existen, sin embargo, muchos mitos sobre héroes ancestrales, entre los cuales Cook puede encajar con facilidad. Pero yo creo que ambas nociones tienen que extenderse para comprender la construcción de mitos en la cultura occidental. Los mitos en su sentido clásico de bistorias sagradas pueden estar pasados de moda, pero los modelos míticos no. Aplico el concepto de "modelo mítico" de dos modos: primero, un mito importante o paradigmático puede servir como un modelo para otros tipos de construcción mítica. Segundo, y más importante, un "modelo mítico" se refiere a una serie de ideas subyacentes (una estructura mítica o grupo de mitemas) empleados en distintas formas narrativas mayores. Estos [bloques de] series de ideas son "estructuras de larga duración" que se adjuntan a formas narrativas mayores tales como la ficción, historia o biografías. Las condiciones históricas juegan, obviamente, un pa- 
pel a la hora de resucitar un modelo mítico enterrado en una tradición; y las condiciones políticas y sociales pueden promover un modelo mítico particular, convirtiéndolo en dominante, o ayudar a inventar un nuevo modelo mítico, basado en los antiguos que ya no son adecuados a los tiempos que corren. Así pueden surgir modelos míticos en distintos contextos, suplementando mitos reales de héroes ancestrales que también han sido creados. Éstos últimos mitos no son historias sagradas en el sentido literal del término, sino que tienen un poder similar y son exactamente isomórficos con historias (leyendas) sobre los ancestros. Así los varios mitos sobre Cook -por ejemplo, el "humanista"- expresa la idea del explorador apropiado a la propia percepción que la civilización tiene de sî misma y contrasta con mitos anteriores, tales como los de un Cortés, un Pizarro, o un Drake, que ya no son relevantes para una edad más liberal e "iluminada". La persona viva se subsume totalmente en el mito y, de hecho, es irrelevante si exceptuamos las notas a pie de página (Obeyesekere 1992: 10-11) ${ }^{21}$.

Toda la humanidad, insiste Obeyesekere, actúa de un modo racional y práctico, por ello ataca al relativismo cultural ${ }^{22}$ que extraña a los nativos, que les convierte en "otros", que los somete, en última instancia, a postulados analíticos que los esclavizan a la costumbre y lo que es peor, a los mitos.

A la etnografía de Obeyesekere no le preocupa mantener un cierto tipo de esencialismo, el que procede de reconocer la común humanidad de todos los seres humanos, por ello le importa más el modo de pensar que los modos de pensamiento:

No soy partidario de eliminar las diferencias; sino de difuminarlas, viendo las similitudes estructurales y de otros tipos bajo las diferencias substantivas, y, cuando esas diferencias existen, intentar entenderlas teóricamente aunque no en los términos de una teoría que aísla las culturas como especies. Para mudar a la antropología a los inciertos territorios liminares del futuro uno debe descongelar el mundo de los nativos y abrirlo a los múltiples universos que contiene. Al mismo tiempo uno debe abrir el mundo encajonado de los teóricos de la etnografía que dibujarán círculos de tiza en torno a las islas de historia y, de modo no pretendido, haciendo exóticas sus culturas, ignorando el sufrimiento humano y el dolor, así como obviando la lucha política, la colonización, o la conquista sobre la que los activistas miran hacia el pasado con furia (Obeyesekere en Borofsky 1997: 272).

${ }^{21}$ El subrayado es mío.

22 "La doctrina del relativismo cultural aisla al otro como una especie y acentúa nuestra predilección por hacer exótica la otra cultura. Esto no significa que los etnógrafos, no deban documentar las prácticas que son diferentes de las suyas, ésa es precisamente su tarea; sino que deben hacerlas inteligibles mediante mecanismos que son comunes a todos los seres humanos. El principio hermenéutico de convertir a lo familiar en extraño y lo extraño en familiar podría ser otro modo de abordar esta cuestión. No es una paradoja, creo, reclamar que las diferencias culturales pueden coexistir con semejanzas familiares y similitudes estructurales. Es el relativismo cultural lo que inhibe su reconocimiento" (Obeyesekere en Borofsky 1997: 272). 
Obeyesekere siente ira por el modo en el que Sahlins interpreta el comportamiento de los nativos a partir de los diarios de Cook y otras informaciones existentes, fundamentalmente escritas por occidentales. Su cuidado metodológico no se preocupa tanto, a diferencia de su contrincante, por establecer el contexto concreto en el que se producen y escriben los textos, que generalmente no se redactaban a bordo o en las horas inmediatas posteriores a los sucesos que tan vívidamente describen, sino por ciertos postulados ideológicos que anulan la común humanidad de los nativos. Ni siquiera la sorprendente homogeneidad en cuanto a la organización de los contenidos, a los estilos descriptivos ${ }^{23}$, son objeto de análisis por parte de los antropólogos ${ }^{24}$. Obeyesekere tiende a limitar su análisis a las evidencias del texto ya que da por supuesta la trama narrativa en la que se engarza. Acontecimiento o evidencia tras evidencia, su preocupación es mostrar que existen interpretaciones y explicaciones alternativas a las que da Sahlins, sin embargo, y ésta es en mi opinión la máxima debilidad de su libro, es incapaz de construir una visión alternativa coherente e integrada.

No obstante, tras la exhibición analítica, las elogiosas reseñas que aplauden una antropología políticamente correcta, surgida de la ira que sienten los que han sufrido la colonización occidental no hay un argumento alternativo. Su heroica resistencia a los planteamientos de Sahlins no nos ofrece, para aquellos que trabajamos con ese tipo de fuentes en el Pacífico, una verdadera objeción de conjunto. De hecho, tras las diferencias que muestran ambos autores, a pesar del durísimo lenguaje que emplean uno contra el otro, sus posiciones no son tan incompatibles. Sin duda la imagen histórica que se ha construido de Cook tiene mucho de modelo mítico, pero jelimina ese hecho que los hawaianos, sin perder de vista su perspectiva práctica que reclama Obeyesekere, consideraran a Cook una encarnación del dios de la fertilidad Lono? ¿no es posible que una parte de esa sociedad lo considerara un dios, otra un potencial aliado contra otros grupos rivales de esa u otras islas del archipiélago y otros, simplemente, una amenaza? ¿qué tipo de juego de intereses y funciones locales reforzaba Cook con su aventurado comportamiento?

\footnotetext{
${ }^{23}$ Por ejemplo, en esta época los diarios son una descripción en la que predomina de un modo decisivo lo visual y desaparecen los olores, las sensaciones, los temores o las euforias, los acontecimientos humanos de la rutina de la vida cotidiana.

${ }^{24} \mathrm{He}$ abordado este tema de un modo más exhaustivo en mi libro: En la Costa de la Niebla: El paisaje y el discurso etnográfico ilustrado de la expedición Malaspina en el Pacifico (Monge 2002).
} 


\section{BEBIENDO KaVA EN VAVA'U, TONGA ${ }^{25}$}

Cambiemos ahora de escenario, abandonemos el teatro de un drama para trasladarnos a uno de esos enclaves del Pacífico que han alimentado nuestra visión de un paraíso en la tierra. Cook las llamó islas de los Amigos, pues sus habitantes pronto destacaron por exhibir esa cualidad ${ }^{26}$. Hoy esas islas se conocen con el nombre de Tonga y es una de las pocas unidades políticas precoloniales que han sabido y podido trazar su propio curso y permanecido independientes. De hecho, Tonga es una monarquía constitucional polinesia con un perfil fuertemente cristiano en el que los estamentos y el parentesco siguen estructurando la sociedad, donde la tierra no se puede comprar, ya que la asigna en parcelas el rey a sus súbditos y no es posible que los extranjeros la posean.

En las islas de los Amigos $^{27}$, Cook se comportó de un modo semejante a como lo hizo en sus otras escalas oceánicas (incluidas entre ellas, la infausta Hawai). Aunque se ha querido justificar la muerte de Cook en Hawai como una consecuencia de su cambio de carácter, se mantiene que, a lo largo de tercer viaje pasó de ser un personaje tolerante, diplomático e interesado por las culturas ajenas, a un capitán colérico e impaciente. Lo cierto es que Cook, a pesar de sus contadas explosiones temperamentales (que no son otras, insisto, que las que generalmente podemos ver a través de sus propios diarios), no encaja muy bien en un caso de doble personalidad, a pesar de lo que defiende Obeyesekere, en una suerte de Dr. Jekill y Mr. Hide, de un Próspero y un Kurtz.

${ }^{25}$ Este epígrafe se basa en un texto propio inédito anterior: "Drinking Kava with 'Vavao' Islanders: The Malaspina Expedition in the Tongan Islands (1793)", presentado en el XVIIIth International Congress of History of Science, Hamburgo y Munich, 19 agosto de 1989.

${ }^{26}$ Las islas de los Amigos, junto con Tahiti y las islas de la Sociedad, son los enclaves que han sustentado la imagen occidental del paraíso polinesio, un lugar de vida fácil, sensual, de clima ideal y paisajes deslumbrantes. De todas esas islas, es Tahití, la que sirve de inspiración a los paisajes que mejor reflejan esa imagen idílica. Aquellos que quieran tener una perspectiva más actual, menos idealizada, pueden leer el libro de viajes The Happy Isles of Oceania: Paddling the Pacific (Theroux 1992).

${ }^{27}$ Las naves de las distintas expediciones de Cook permanecieron en las islas, durante el segundo viaje en dos ocasiones, entre el 2 y el 8 de octubre de 1773 visitó 'Eua (Middelburg) y Tongatapu (Amsterdam), y el 26 y el 29 de junio de 1774, Nomuka (Rotterdam); durante la tercera expedición navegó y exploró distintas islas de Tonga de un modo sorprendente en él, pues apenas recaló en las mismas entre el 28 de abril y el 17 de julio de 1777; la expedición Malaspina, que recaló en Vavao (Vava'u) en el archipiélago más septentrional de Tonga, permaneció en la isla desde el 20 de mayo al 1 de junio de 1793 . 
En Tonga los expedicionarios sufrían robos por parte de los nativos como en cualquier otra isla, y del mismo modo trataban de contrarrestarlos con las ayudas de los jefes, quienes de modo paradójico no sólo imponían el orden y castigaban, sino que eran, además, los que en última instancia iban a recibir esos objetos robados por sus súbditos. Si la autoridad del jefe no se imponía, los visitantes secuestraban a los jefes y forzaban la devolución de lo robado a cambio de la liberación de su líder.

Del mismo modo que en Hawai, en Tonga llevaron a cabo sus rutinas de mantenimiento: aguada, repostar con alimentos frescos mediante el comercio con los naturales, reparar los desperfectos de los buques, lavar la ropa y descansar; en cuanto a la actividad científica, se ocupaban de establecer la latitud y longitud de las islas fijándolas con mediciones astronómicas (para lo que tenían que levantar un observatorio en tierra); trazar cartas náuticas y levantar planos; herborizar, capturar especies vivas y llevar a cabo descripciones geológicas; examinar las cualidades y costumbres de los naturales y establecer buenas relaciones con ellos. Su guión de actividades se repite en cada una de sus recaladas y, del mismo modo, así se refleja en sus diarios. De hecho, las propias monografías sobre los lugares visitados, sus descripciones de las sociedades y culturas sobre las que investigan se asemejan en su estructura y obedecen a un patrón explicativo idéntico.

Al igual que en Hawai, aunque con diferentes resultados, Cook trató de establecer buenas relaciones con los nativos y participar en cuanta ceremonia le fue posible. Tanto es así que es el primer explorador que nos describe el inas $^{28}$. A pesar de no comprender la mayor parte de su significado, su meticulosa descripción es sorprendentemente rica en detalles. Sin duda éste es uno de los fragmentos de sus diarios que le han proporcionado mayor reputación como gran explorador y "etnógrafo". No obstante sus méritos, hoy sabemos gracias a otras fuentes de viajeros y a la propia memoria oral bien recogida en la actualidad en los archivos del Palacio Real de Nuku'alofa (la capital de Tonga), que Cook arriesgó su vida varias veces al violentar insistentemente los tabúes o prohibiciones que debían seguir durante la celebración de los rituales. ¿Cómo debemos interpretar su comportamiento? ¿bajo qué esquema explicativo ubicaríamos su muerte si se hubiera producido en la isla de los Amigos? ¿con qué trama de análisis teórico, la de Sahlins o la de Obeyesekere, nos sentiríamos más cómodos? o lo que es más importante ¿cómo podríamos construir argumentos consistentes más que aspirar a verdades inmutables?

28 'inasi es una ceremonia en la que los primeros frutos del año se ofrecen al rey sagrado o Tu'i Tonga como parte de un ritual político-religioso que involucra a toda la nación (Bott y Tavi 1982: 173). 
Sin duda a los jefes de Tonga no les importó mostrar aspectos prohibidos de su ritual a un extraño "que pasaba por allî" y con el que habían entablado una fructífera relación comercial y de amistad. Con reticencia, y cierta tolerancia, le permitían asistir a sus ceremonias siempre y cuando se quitara la camisa y soltara el pelo. De hecho la ruptura de la etiqueta por parte de Cook en el ritual que presenció se unió a la anomalía que suponía que los nativos celebraran este inasi no para conmemorar la llegada de la estación de la cosecha sino para conceder al hijo del rey sagrado o Tu'i Tonga (ante la insistente presión de la mujer de éste) algunos de los rasgos y privilegios del propio rey (algo absolutamente sin precedentes en su historia) ${ }^{29}$.

No voy a entrar ahora en un análisis detallado de esos encuentros históricos en Tonga entre Cook y, más tarde, otros "exploradores-observadores" como Malaspina. Gracias a esos documentos, los de otros exploradores y, sobre todo, la memoria oral, hoy recogida en el archivo real arriba mencionado, podemos recomponer la compleja dinámica y posibles interpretaciones que los comportamientos y acontecimientos de los encuentros tuvieron en su día. Tal y como hemos visto en la polémica explicación de la muerte de Cook, esta relación entre exploradores y tonganos es un caso de estudio particularmente rico para poner a prueba los procedimientos interpretativos que ha desarrollado la práctica teórica de la antropología.

Cook, como muestra su diario, no era un antropólogo avant la letre, sus indudables dotes descriptivas, su perspicacia y las circunstancias que vivió le convierten en uno de los mayores exploradores del siglo XVIII. Puso "en orden" y dio una primera imagen ${ }^{30}$ del conjunto del Pacífico sur, acabando con la fantasía del continente austral (que en modo alguno podía ser Australia). Desde la perspectiva actual, uno de los méritos más sobre-

29 En realidad Cook asiste, como ya he indicado, a un ritual anómalo que tiene consecuencias en el desarrollo y estabilidad política de la isla. En este caso es testigo, sin saberlo, de un cambio histórico sin precedentes dentro de Tonga. Véase Bott y Tavi (1982).

${ }^{30}$ Aunque al referirme a la imagen hacía alusión a mucho más que a su representación gráfica. Son textos absolutamente claves para aquellos interesados por estas cuestiones los trabajos de Smith (1985 y 1992). La obra gráfica completa de las expediciones de Cook fue publicada por Smith y Joppien (1985-88) en tres volúmenes. Para aquellos interesados por la misma en la expedición Malaspina, véase Sotos Serrano (1982). Del Diario General de la expedición hay dos ediciones: Palau, Saiz y Zabala (1984), y la edición crítica, en varios tomos, cuya editora general es María Dolores Higueras. El tomo de mayor interés para los antropólogos, junto con los diarios, es el que editó Pimentel (1993). 
salientes de sus escritos radica en su capacidad de describir y transmitir información sobre lo que no sabía. Su estilo ayudaba considerablemente en su narración, pues no era hombre aficionado a las largas elucubraciones filosóficas que caracterizan la prosa culta de los hombres de la Ilustración.

En Tonga, por ejemplo, una de las "piedras de toque" para la inclusión o la obtención de información más delicada sobre la organización social y sus valores pasa por la participación en la ceremonia de la bebida del kava en un círculo ritual, que manifiesta el rango de sus participantes, los incluye en la comunidad y permite poner al día el entramado de relaciones sociales que sustenta la comunidad, así como, simplemente, participar socialmente en la misma. Ese conocimiento más profundo de la sociedad visitada pasaba por la ingestión del kava, una bebida de efectos hipnóticos, que se producía masticando la raíz del Piper Mestbicum y mezclándola luego con agua. Los exploradores, al ver su preparación, evitaron su ingestión, excepto algunos como Cook, que, en contadas ocasiones, cuando no tenían más remedio y sin llegar a participar plenamente en él, llegaban a probarlo.

Un análisis pormenorizado de este acontecimiento, enmarcado en su visita, nos permitiría, como en el caso de la muerte de Cook, profundizar y elaborar una antropología histórica de los encuentros en los que habríamos de tratar de integrar y abarcar ambos universos culturales, ahora en contacto, y la naturaleza de sus relaciones en la génesis de nuevos universos de significado cultural.

Los encuentros, su análisis e interpretación son, sin duda alguna, y como he pretendido mostrar en la encendida polémica entre Cook y Obeyesekere, un campo de investigación particularmente fructífero que nos exige un gran cuidado metodológico. De hecho, teoría y metodología viajan juntas en la práctica antropológica. ¿No es acaso el Pacífico, tal como he intentado mostrar a lo largo de estas páginas, un espacio tan "real" como inventado?

\section{A VUELTAS CON LA INTERPRETACIÓN}

Tal como afirma Borofsky, "la incertidumbre a la hora de analizar el pasado no impide nuestros análisis, solamente encuadra cómo lo hacemos" (1997: 277). Podemos valorar las evidencias que uno y otro, Sahlins y Obeyesekere, aportan en su sonada polémica, extraer conclusiones alternativas o conceder mayor acierto a uno y otro. Como ya he mostrado, una lectura cuidadosa de los postulados básicos de uno y otro hace difícil entender las razones teóricas y éticas que les enfrentaron de un modo 
tan enconado. Tras este periplo por el Pacífico, llegan las grandes preguntas: ¿Podemos los antropólogos hablar sobre el "otro"? En realidad, ambos creen en esa posibilidad. El problema, una vez más, radica en la interpretación, del mismo modo que Cook pudo ser interpretado por los hawaianos como un dios, Obeyesekere adjudica a Sahlins el papel de opresor

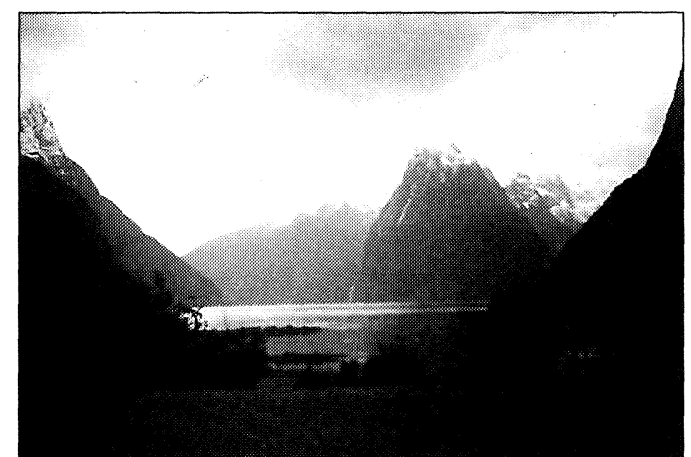

Figura 3.-Milford Sound. Pico y comienzo del fiordo. Nueva Zelanda. e imperialista.

Para el primero es posible hablar sobre los "otros" si somos capaces de construir un argumento bien razonado, que se apoye bien en buenos razonamientos y las evidencias (Obeyesekere en Borofsky 1997: 69); mientras que para Sahlins:

una comprensión intercultural no descansa simplemente sobre una biología común, una fisiología de la percepción que no permita a los antropólogos y sus interlocutores estar de acuerdo sobre los referentes empíricos de su charla que, de otra manera sería distinta. Algunas veces es al contrario: la posibilidad de la antropología consiste en operaciones simbólicas mutuas y comunicables, del tipo que puede hace lógica e intelectualmente incomunicable lo que es empíricamente increíble. 'Este pan es el cuerpo de Cristo.' 'La patata dulce es el cuerpo de Lono,' [...]. La cuestión no es simplemente percepción sino juicio: ¿qué es lo que hay, y cómo esta relacionado con qué otras cosas? (Sahlins en Borofsky 1997: 274).

Le preocupan las relaciones significativas, las afirmaciones con sentido y no simplemente las sensaciones perceptivas.

En suma, para Obeyesekere las nuevas fronteras de la antropología descansan en el conocimiento de las otras epistemologías, en el desarrollo de una epistemología transcultural; para Sahlins, sin embargo, son:

las relaciones fundamentales de la sociedad [las que] están presentes en el microcosmos del intercambio simbólico. Si la afirmación de un "yo" es una reivindicación de poder, la reversibilidad del "yo" y "tu" es alternativamente competición o reciprocidad cuando el reconocimiento mutuo de la persona es el germen de la sociabilidad. Los principios elementales de la sociedad humana son intrínsecos a las estructuras del discurso simbólico. La antropología es un intento de superar los límites parroquiales tradicionales de dichos discursos. Por lo tanto, critica a los antropólogos y sus conceptos de cultura tanto como desees por su 
etnocentrismo e imperialismo, siempre existirán relaciones humanas contradictorias en su proyecto (Sahlins en Borofsky 1997: 276).

Por eso, la interpretación, que es un mecanismo donde los procesos simbólicos se explotan sistemáticamente, no sólo es un elemento necesario para la antropología, sino, también, y sobre todo, central en nuestra actividad como seres humanos y antropólogos.

\section{BIBLIOGRAFÍA CITADA}

BeAgleHole, John C. 1974. The Life of Captain Cook. Stanford: Stanford University Press.

- (ed.). 1955-1969. The Journals of Captain Cook on His Voyages of Discovery. Cambridge: Cambridge University Press (for the Hakluyt Society).

- (ed.). 1955. The Journals of Captain Cook on His Voyages of Discovery: I. The Voyage of the Endeavour, 1772-1775. Cambridge: Cambridge University Press (for the Hakluyt Society).

- (ed.). 1961. The Journals of Captain Cook on his Voyages of Discovery: II. The Voyage of the Resolution and Adventure, 1772-1775. Cambridge: Cambridge University Press (for the Hakluyt Society).

- (ed.). 1967. The Journals of Captain Cook on His Voyages of Discovery: III. The Voyage of the Resolution and Adventure, 1776-1780. 2 partes. Cambridge: Cambridge University Press (for the Hakluyt Society).

BergendorfF, SteEn; Ulla Hasager y Peter Henriques. 1988. "Mytopraxis and History: On the Interpretation of the Makahiki". Journal of the Polynesian Society 97: 391-408.

BOROFSKY, ROBERT. 1997. "Cook, Lono, Obeyesekere, and Sahlins". Current Anthropology 38 (2): 255-282.

BotT, Elizabeth y TAVI. 1982. Tongan Society at the Time of Captain Cook's Visits. Discussions with Her Majesty Queen Salote Tupou. Auckland, Nueva Zelanda: The Polynesian Society.

Craig, Robert. 1978. Captain Cook in the Pacific. Laie, Hawaii: Brigham Young University.

DeNING, GREG. 1982. "Sharks that Walk on the Land: The Death of Captain Cook". Meanjin 41: 427-437.

FirTh, RAYMond. 1983 [1936]. We, The Tikopia: A Sociological Study of Kinship in Primitive Polynesia. Stanford: Stanford University Press.

Friedman, Jonathan. 1985. "Captain Cook, Culture, and the World System". Journal of the Pacific History 20: 191-201.

GeERTZ, ClifFord. 1995. After the Fact: Two Countries, Four Decades, One Anthropologist. Cambridge: Cambridge University Press.

HERzFELD, MichaEl. 2001. Anthropology: Theoretical Practice in Culture and Society. Malden, Massachusetts: Blackwell.

KUPER, ADAM. 1999. Culture. The Anthropologists' Account. Cambridge, Mass.: Harvard University Press.

LANDín CARRASCO, Amancio. 1984. Islario español del Pacífico: Identificación de los descubrimientos en el Mar del Sur. Madrid: Ediciones de Cultura Hispánica. 
Melville, Herman. 1983. Typee: A Peep at Polynesian Life. Harmondsworth: Penguin Books.

MONGE, Fernando. 1992. "El texto como contexto. Los diarios de viaje ilustrados al Pacífico como fuente etnográfica". Arbor 143 (564): 93-114.

- 2002. En la costa de la niebla: El paisaje y el discurso etnográfico ilustrado de la expedición Malaspina en el Pacífico. Madrid: CSIC.

OBEYESEKERE, GANANATH. 1992. The Apotheosis of Captain Cook: European Mythmaking in the Pacific. Princeton: Princeton University Press.

- 1997. "Comment: Cook, Lono, Obeseyekere, and Sahlins". Current Anthropology 38: 267-272.

Palau, Mercedes; Blanca Sáinz y Aránzazu Zabala (eds.). 1984. Viaje científico $y$ político [...] por los capitanes de navio D. Alejandro Malaspina y D. José Bustamante: Diario de viaje de Alejandro Malaspina. Madrid: Ediciones El Museo Universal.

Pimentel Igea, Juan (ed.). 1993. La Expedición Malaspina, 1789-1794. Tomo V: Antropología y noticias etnográficas. Madrid: Ministerio de Defensa-Lunwerg Editores.

SAHLINS, MARSHAll. 1974. Stone Age Economics. Londres: Tavistock.

- 1981. Historical Metaphors and Mythical Realities: Structure in the Early History of the Sandwich Island Kingdom. Ann Arbor: University of Michigan Press.

- 1985. Islands of History. Chicago: University of Chicago Press.

- 1988. Islas de Historia: La muerte del capitán Cook. Metāfora, antropología e bistoria. Barcelona: Gedisa. ....

- 1989. "Capitan Cook at Hawaii". Journal of the Polynesian Society 98: 371-425.

- 1995. How "Natives" Think: About Captain Cook, for Example. Chicago: Chicago University Press.

- 1997. "Comment: Cook, Lono, Obeyesekere, and Sahlins". Current Anthropology 38 (2): $272-276$.

SMITH, BERNARD. 1985. European Vision and the South Pacific. New Haven: Yale University Press

- 1992. Imagining the Pacific: In the Wake of the Cook Voyages. New Haven: Yale University Press.

- y R. JopPIEn (eds.). 1985-1988. The Art of Captain Cook's Voyages. New Haven: Yale University Press.

SOtOS SERRANO, CARMEN. 1982. Los pintores de la expedición de Alejandro Malaspina. Madrid: Real Academia de la Historia.

Theroux, Paul. 1992. The Happy Isles of Oceania: Paddling the Pacific. Londres: Penguin Books.

Wilson, Edward O. 1975. Sociobiology: The New Synthesis. Cambridge, Mass: Harvard University Press.

WOLF, ERIC R. 1982. Europe and the People without History. Berkeley: University os California Press.

WoOdCock, George. 1983. "Introduction", en H. Melville, Typee: A Peep at Polynesian Life: 7-27. Harmondsworth: Penguin Books. 


\section{ÚLTIMOS VOLÚMENES APARECIDOS EN LA BIBLIOTECA DE DIALECTOLOGÍA Y TRADICIONES POPULARES}
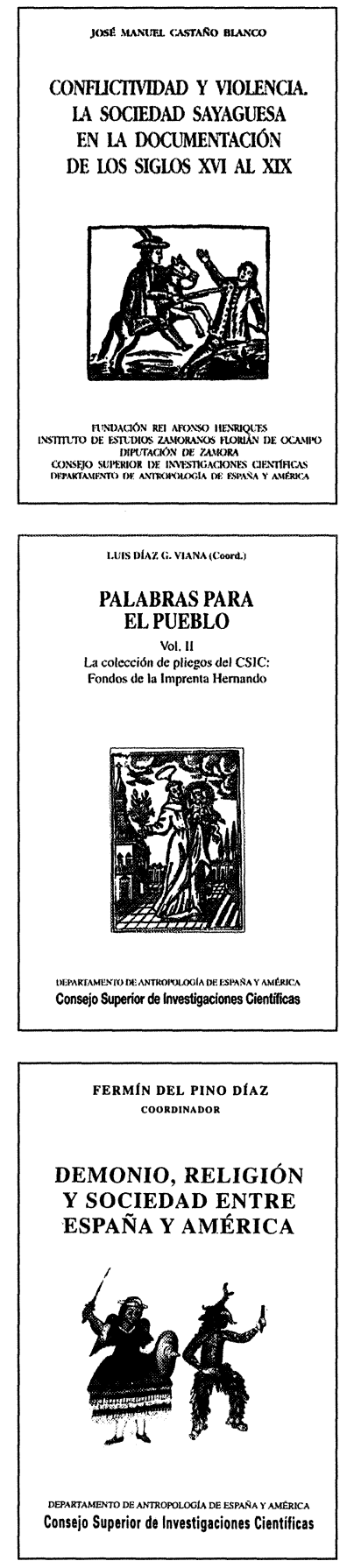
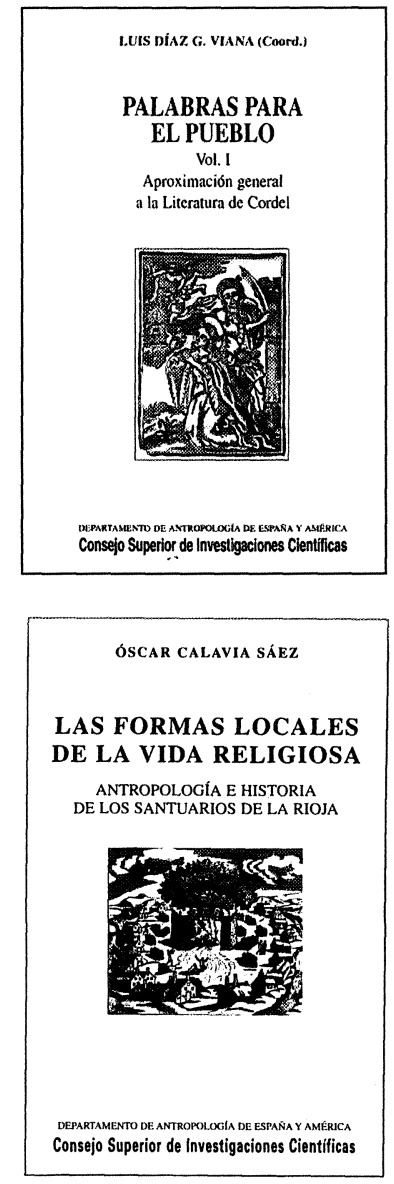

FRANCISCO CASTILLA URBANO

EL ANÁLISIS SOCIAL DE JULIO CARO BAROJA: EMPIRISMO Y SUBJETIVIDAD

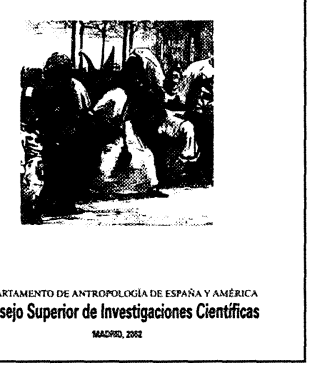

